\title{
O mundo do comércio, um mundo das mulheres: Pensando práticas comerciais em Mindelo, Cabo Verde
}

\author{
VINICIUS VENÂNCIO \\ Universidade de Brasília, Brasília, Distrito Federal, Brasil \\ DOI 10.11606/issn.2316-9133.v28i1p33-49
}

\begin{abstract}
resumo O objetivo deste trabalho, realizado em Mindelo, ilha de São Vicente, Cabo Verde, é compreender o papel do comércio transnacional nas vidas das mulheres que tecem as redes que dão vida a ele. Meu interesse é refletir sobre o contexto social em que a mulher é figura central tanto no âmbito doméstico - enquanto mulher-mãe - quanto no domínio do público - como comerciante com papel central nas ruas, mercados e lojas, não somente na cidade, mas em rotas transnacionais. Para realizar tal análise, apresentarei as rotas mais comuns utilizadas por essas mulheres para adquirir os produtos que abastecem as suas lojas, destinos esses que muitas vezes confluem com os migratórios. Por ser desempenhado majoritariamente por mulheres, investigo também como se dá a congruência entre dois mundos que rotineiramente são colocados enquanto opostos, a casa e a rua, a partir da noção de centralidade feminina no âmbito doméstico, tão presente nos estudos sobre o arquipélago.
\end{abstract}

palavras-chave Comércio transnacional, Mulheres, Cabo Verde, Mindelo

The world of markets, a world of women: rethinking trade practices in Mindelo, Cape Verde

abstract The objective of this work, held in Mindelo, São Vicente Island, Cape Verde, is the role of transnational trade in the lives of women who weave as nets that give life to it. My interest is the context about the social in which the woman is a central figure both in the home space - while the mother woman - and in the public domain - as the trader in the central role in the streets, markets and shops, not only in the city, but transnational routes. To get such an analysis, present the most common changes used by these women to get products that are more abundant like their stores, the destinations that often have merged with the migratory. By being classified as predominantly by women, investing also as a congruence between two worlds that are routinely as sobrana, a house and a street, from the notion of female centrality, are so present in the studies on the archipelago.

keywords Transnational trade, women, Cape Verde, Mindelo 


\section{O comércio transnacional em Cabo Verde}

As práticas comerciais desenvolvidas por mulheres na costa oeste do continente africano não são recentes na história da região, como nos apresenta Brooks Jr. (1976) com o caso das signares, uma classe de mulheres que residia na área que vai de Saint Louis à Gorée, hoje territórios pertencentes ao Senegal, que controlavam parte considerável do comércio entre a costa oeste africana (e seu interior) com países europeus, especialmente Portugal, que fazia uso da proximidade de Cabo Verde com a região para manter esse fluxo comercial.

Mesmo com a longevidade da circulação de mulheres do continente africano, nele e para além dele cuja finalidade são práticas comerciais, essas práticas vêm chamando a atenção nas últimas décadas, seja de pesquisadores, como é o caso desse trabalho, seja por parte das grandes organizações internacionais, como o Banco Mundial (BRENTON et al, 2013), ou até mesmo por parte dos governos nacionais, que visam controlar a circulação dessas mulheres e dos produtos que elas portam pelas fronteiras (HANSEN, 20000). Isso porque, de leste a oeste, do Saara à Cidade do Cabo, é sempre possível encontrar mulheres tentando ganhar a vida através do comércio, sejam as bideiras ${ }^{2}$ da Guiné Bissau ou as traders do sul da África (MOUTINHO; LIBERATO, 2018).

Em Cabo Verde, país-arquipélago lusófono localizado na costa oeste do continente africano, não é diferente. Lá, as mulheres que se envolvem com as mais distintas práticas de comércio podem ser conhecidas como rabidantes, termo que, de acordo com Grassi, "significa em crioulo de Cabo Verde, 'dar a volta', 'desenrascar-se', e é utilizado para indicar alguém que é muito hábil a convencer os outros” (GRASSI, 2003, pp. 23).

Embora o termo rabidante englobe um grupo muito mais heterogêneo de experiências, podendo as rabidantes serem

1. vendedoras eventuais que, a depender do contexto e da necessidade, expõem produtos na calçada de suas casas para dali obterem um dinheiro extra; 2 . comerciantes que vendem em feiras, mercados, ou mesmo em um ponto fixo na rua, mas que não viajam para adquirir os produtos da venda; (ou) 3. mulheres que realizam viagens regulares para outros países e que vendem no mercado local, em estabelecimentos próprios ou para terceiros (LOBO, 2012, p. 321),

\footnotetext{
${ }^{1}$ Uma versão anterior deste trabalho foi discutida no Seminário "Performances de Gênero em Cabo Verde". Neste contexto, agradeço, especialmente, aos comentários das professoras Clementina Furtado e Carmelita Silva, que me ajudaram a enriquecer a análise. De igual modo, agradeço às instigantes proposições feitas pelas pareceristas.

${ }^{2}$ As bideiras são mulheres que compram junto de múltiplos pequenos produtores os excedentes da produção, por exemplo de arroz ou peixe, reunindo uma quantidade apreciável de mercadoria, que depois, distribuem em grosso ou a retalho noutros mercados, a partir da sua própria a casa, ou através kulkadores que revendem as mercadorias junto dos consumidores. Estes agentes e circuitos informais controlam o comércio dos bens alimentares, incluindo fruta, vegetais, arroz produzido no país, peixe (DOMINGUES, 2000, p. 301).
} 
me aterei ao decorrer do trabalho ao terceiro grupo descrito. Este recorte se dá devido às "redes de comércio transnacional"3 (GRASSI, 2003, p. 78) desenvolvidas por essas mulheres a partir de Cabo Verde em direção a diversos países na rota do Atlântico, sendo alguns desses destinos coincidentes com os dos fluxos emigratórios.

Ainda, essas práticas comerciais transnacionais ocorrem dentro do que Ribeiro (2010) compreende como globalização econômica não-hegemônica, que, dentro do contexto mundial, é "formada por mercados populares e fluxos de comércio que são, em grande medida, animados por gente do povo e não por representantes das elites" (RIBEIRO, 2010, p.21). Essa globalização econômica não-hegemônica geralmente ocorre através do que Nordstrom (2007) chama de shadows, que seriam momentos de ilegalidades - ou fuga do rígido controle estatal - no percurso que vai da produção dos objetos até a sua chegada nas mãos do consumidor.

As comerciantes cabo-verdianas representariam a globalização por baixo por serem as responsáveis pela inserção local de boa parte dos bens de consumo produzidos a nível global, que são almejados pela população. Essa situação acaba por se inserir em um contexto de globalização popular, no qual as camadas populares tiram proveito dos fluxos de riqueza e "democratizam" o acesso aos bens. Vale pontuar que o fenômeno de ir para outros países buscar produtos para revenda não é algo restrito à Cabo Verdiano e nem aos contextos africanos, mas sim uma prática rotineira dentro do contexto de globalização popular (RIBEIRO, 2010, p.31), que é construída justamente a partir desses centros de comércio, viagens e fluxos desenvolvidos pelas e pelos comerciantes, embora cada caso seja dotado de suas especificidades. Contudo, o que singulariza a circulação internacional das caboverdianas, tendo como foco o comércio, em comparação com outras, como a brasileira, é a confluência das redes comerciais tecidas por elas com os fluxos emigratórios que partem de Cabo Verde.

Os fluxos que estas mulheres tecem são cruciais para o comércio mindelense, uma vez que elas estão inseridas em um meio com escassa produção industrial, demandando a importação de quase tudo que será consumido pela população. A centralidade do comércio reflete diretamente no PIB da ilha, sendo o comércio o segundo principal gerador de riqueza de São Vicente (INE, 2016).

Tendo esse ponto de partida, o presente artigo partirá da análise das práticas comerciais transnacionais desenvolvidas por essas mulheres em Mindelo, ilha de São Vicente, ${ }^{4}$ e terá como objetivos: i) compreender, o(s) porquê(s) da centralidade das mulheres nesse ramo e, assim, da recorrente afirmação de que "a mulher teria mais jeito para comércio"

\footnotetext{
${ }^{3}$ Compreendo por comércio transnacional a "circulação de bens e serviços não declarados" (GRASSI, 2007, p. 134), que gera o "comércio de produtos realizado entre agentes económicos sedeados em espaços geográficos situados de um lado e do outro de uma fronteira entre dois países, reporta à contiguidade dos espaços nos quais se realizam as trocas comerciais" (LOPES, 2007, p. 36).

${ }^{4}$ A pesquisa de campo com as comerciantes transnacionais foi realizada em Mindelo, cidade central da ilha de São Vicente, entre janeiro e março de 2017.
} 
(GRASSI, 2003, p.162); ii) analisar a relação da família com as práticas comerciais; iii) observar o comércio transnacional a partir da lógica da globalização popular e, assim, compreender a importância dos que elas desenvolvem para o comércio local e, a partir dos relatos de viagens para o Brasil, iii) trazer um pouco do comércio quando elas estão na posição de compradoras.

Além da compreensão da circulação das mulheres cabo-verdianas entre esses dois mundos e dos percursos traçados por elas na tentativa de garantir a reprodução econômica e social dos seus grupos domésticos, a pertinência do estudo sobre comércio no arquipélago se dá pela necessidade de ampliar as reflexões iniciadas por pesquisas anteriores (GRASSI, 2003; LOBO, 2012; SILVA, 2012), tendo em vista a escassez de trabalhos sobre comércio transnacional em Cabo Verde que tenham como locus qualquer uma das ilhas que não seja a ilha de Santiago.

Para a pesquisa, foram entrevistadas mulheres donas de boutiques na Morada, bairro central de Mindelo, Monte Sossego e Fonte Filipe, além de donas de quiosques na Praça Estrela, aglomerado comercial próximo ao Mercado de Peixes, com perfis socioeconômicos distintos.

\section{A mulher no comércio em Cabo Verde}

Ainda no aeroporto de Fortaleza, onde fiz escala para pegar o voo direto do Brasil para Cabo Verde, uma senhora brasileira se sentou ao meu lado e começou a conversar enquanto esperávamos o nosso voo. Ao descobrir que eu iria para Cabo Verde, e não para Portugal, como a maioria dos passageiros daquele voo, ela me contou uma coisa que, segundo ela, eu não acreditaria: lá em Cabo Verde eram as mulheres que comandavam o comércio, o que era justificado pelos habitantes de lá como uma habilidade melhor desenvolvida pelas mulheres do que pelos homens.

Ao aportar em terras sampadjudas, ${ }^{5}$ pude asseverar a existência do fenômeno apresentado pela senhora no aeroporto e que, antes disso, já era delimitado enquanto meu projeto de pesquisa. Fosse no Mercado de Peixes, nas ruas da cidade vendendo hortaliças, cigarros e balas, nos quiosques da Praça Estrela ou nas lojas, as mulheres representavam a maior parte das comerciantes.

O domínio do comércio local pelas mulheres está bem representado nos dados estatísticos: o número de mulheres representa o quadruplo do número de homens dentre as 6822 pessoas que trabalhavam com comércio em todo o território nacional, de acordo com o censo realizado em 2010 (INE, s.d.). A centralidade da mulher no mundo do comércio acaba sendo reflexo do que acontece no âmbito doméstico, tornando esses dois mundos um a extensão do outro, uma vez que a centralidade feminina na vida doméstica significa, no contexto cabo verdiano, onde cabe à mulher "a responsabilidade para o sustento e reprodução do agregado” familiar (GRAZI; ÉVORA: 2007, p. 18). Refletindo essa informação, dos 140.685 agregados familiares recenseados em 2016, 46,7\% eram sustentados

\footnotetext{
${ }^{5}$ Referente aquele ou aquilo que é da ilha de São Vicente em crioulo cabo-verdiano.
} 
econômica e afetivamente pelas mulheres e, dentre as famílias chefiadas por mulheres, 27,9\% eram consideradas famílias monoparentais. Essas mulheres veem no comércio informal caminhos para driblar a pobreza, garantindo o sustento de suas famílias.

A predominância das mulheres no comércio transnacional cabo-verdiano se dá pela possibilidade de conjugar o mundo da casa e da rua em uma só atividade, uma vez que, entre os cabo-verdianos, é comum que as mulheres-mães sejam responsabilizadas "socialmente perante situações de sucesso e fracasso na educação e criação dos filhos” (FORTES, 2015a, p. 152). Por isso, elas encontram no mundo do comércio uma atividade que permite que elas assumam a centralidade financeira do grupo doméstico, realizando trabalhos que podem ser feitos em casa, local onde costuma se dar o início das atividades comerciais, além de permitir o maior apoio dos parentes.

E é justamente a família o ponto central que elas apresentaram para justificar a entrada na vida comercial, passando por questões como gravidez imprevista, estratégias para ficar mais próxima dos filhos e forma de aumentar a renda durante a aposentadoria e/ou anos finais da vida. Os argumentos postulados associados a características estruturais da sociedade cabo-verdiana, como a poligamia não-oficial, que viabiliza maior ausência dos pais-de-filho ${ }^{6}$ no auxílio financeiro, a alta emigração masculina e feminização do ambiente doméstico, ajudam-nos a compreender o porquê da replicação da centralidade feminina no âmbito doméstico para o comercial, mostrando que, no contexto analisado, a relação casa e rua não é tão dicotômica como costuma ser apresentada na literatura antropológica. Ainda, vale ressaltar que as razões para a entrada na vida comercial devem ser lidas pela via das múltiplas causalidades.

Para melhor compreender essa teorização, apresentarei as trajetórias de vida de quatro comerciantes, que serão apresentadas em dois grupos mesmo que essas causas elencadas não se constituam como o único fator: as das mulheres que justificam o começo do trabalho com comércio devido à gravidez, as que explicaram pela via da necessidade de estarem mais próximas de seus filhos. Sigamos para os casos.

\section{Quando o início do comércio é atribuído à gravidez}

Júlia, uma das minhas primeiras interlocutoras, tinha, na época da pesquisa, 33 anos. Ela me contou que começou a trabalhar com comércio havia 15 anos, quando engravidou do namorado que tinha na época, pai de seus dois filhos mais velhos, e acabou sendo expulsa da escola. Na eminência de também ser expulsa de casa pelo seu pai, sua mãe, mesmo à distância,

\footnotetext{
6 “Termos comumente utilizados para se referir aquele ou àquela com quem ego teve um filho" (LOBO: 2014, p. 81). Mesmo que a análise da autora se centre na ilha da Boa Vista, a aplicabilidade do conceito se estende ao contexto de São Vicente.
} 
já que estava emigrada em Brockton ${ }^{7}$, enviou para ela dois bidões ${ }^{8}$ para que Júlia pudesse revender os produtos e, então, ter uma renda inicial para dar início à sua família. A partir daí o negócio foi crescendo e, em 2007, ela teve a possibilidade de começar a realizar viagens para comprar os seus produtos, mesmo que sua mãe nunca tenha deixado de enviar bidões para ela, já que o forte de sua boutique são os produtos estadunidenses que sua mãe envia.

A história de Sônia se assemelha muito à de Júlia. Na época com 34 anos, contou-me que começou a trabalhar cedo em uma boutique, já que havia engravidado, também antes de concluir o ensino básico, e seu pai, na época emigrado na Holanda, tentou expulsá-la de casa, assim como ocorrido com Júlia, porém sem sucesso. Mesmo que o pai fosse o principal responsável pela renda da casa, a autoridade do lar centrava-se na mãe, que havia criado ela e seus irmãos. Pelo pai ser visto por eles, na época, como uma figura ausente do cotidiano da família, ele não possuía tamanha autoridade para realizar tal ato, o que possibilitou que sua mãe conseguisse mantê-la em casa. Após anos trabalhando em uma boutique, ela pediu demissão e, com o dinheiro da indenização recebida em seu antigo trabalho, viabilizou a compra das passagens para o Brasil, seu primeiro destino de compras. Assim, deu início ao seu próprio negócio, que funcionou em sua casa até 2013 , quando juntou a quantia necessária para adquirir a sua própria boutique.

\section{Quando o início do comércio é atribuído à necessidade de estar próxima dos filhos}

Célia, comerciante de 50 anos que possui uma boutique em Fonte Felipe, começou as viagens transfronteiriças há 15 anos. Como muitas das cabo-verdianas, morou com o pai de seus quatro filhos por 10 anos, mas nunca foram casados legalmente. Ela viu no comércio uma forma de aumentar a renda do lar e garantir sua autonomia financeira. Antes disso, emigrou três vezes diferentes - por um ano e seis meses para Holanda, nove meses em Luxemburgo e na França por três meses -, mas todas elas "fracassaram". Célia atribui ao insucesso de suas tentativas de emigração ao fato de que seus filhos eram pequenos e não se adaptaram muito bem à convivência com os parentes que cuidavam deles. Ao se fixar definitivamente em Cabo Verde, viu no comércio a possibilidade de garantir o sustento doméstico como alternativa ao projeto migratório que não deu certo. Sem contar com a ajuda de seu pai-de-filho, ela e seu filho mais grande sustentam a sua casa, onde vivem ela, os quatro filhos, de idades entre 31 e 16 anos, e uma neta, filha da sua única filha.

A garra e centralidade da mulher cabo-verdiana podem ser encontrada em todas as histórias apresentadas. Nas duas histórias que justificam a entrada no comércio pela via da gravidez, percebemos elementos que se repetem: a gravidez, os pais das moças que não

\footnotetext{
${ }^{7}$ Cidade no estado estadunidense de Massachusetts, que conta com uma expressiva comunidade de cabo-verdianos. Cerca de 10\% dos 95630 habitantes de Brockton possuem ancestralidade cabo-verdiana, sendo a cidade com o maior nível nos EUA. Fonte: http://www.epodunk.com/ancestry/Cape-Verdean.html acessado em 10.07.17.

${ }^{8} \mathrm{O}$ bidão é um barril que parentes emigrados enviam para os que ficaram em Cabo Verde cheio de produtos, que podem ser tanto presentes quanto artigos para revenda.
} 
aceitam a gravidez e as mães que lutam para mantê-las no seio familiar (e conseguem), tudo isso ocorrendo dentro contexto familiar onde ou a mãe ou o pai são as pessoas que estão emigradas. Ainda, a entrada de Júlia e Sônia no comércio transnacional pode ser justificada tendo em vista que esse trabalho é razoavelmente comum em Cabo Verde, uma vez que quase todas as pessoas possuem um parente emigrado. Ainda, ele é acessível por poder ser feito em casa e seu primeiro investimento vir da própria família, como ocorreu com Júlia.

No caso apresentado no segundo tópico, onde a necessidade de se estar próxima da da família foi a justificativa usada, há, implicitamente, a ideia de que o comércio em Mindelo seria um tipo de trabalho que permitiria a circulação entre público e privado ao mesmo tempo, uma vez que pode ser realizado na própria casa das comerciantes, assim como elas possuem maior liberdade para levar os seus filhos consigo para o trabalho, já que elas seriam as próprias chefes. Essa dualidade entre o público e o privado é o que marca o trabalho desempenhado por essas mulheres, uma vez que elas circulariam entres esses dois mundos a todo momento, tirando-os da categoria de opostos, uma vez que eles atuam, para elas, como complementares.

Em todos os casos, percebe-se uma constante: mulheres que viram no comércio a oportunidade de garantir sustento para elas e seus familiares e que desejam que os seus filhos sigam outros caminhos, para que não tenham a vida de sacrifícios que elas levaram.

Para evitarmos cair na armadilha retórica da desestrutura familiar, que vem conquistando tantos teóricos fora da antropologia, duas noções são necessárias para entender a ausência masculina e centralidade feminina dentro do agregado doméstico. A primeira é a noção de

waithood, (wait = espera + o sufixo hood, como em childhood ou adulthood) que pode ser traduzido como idade de espera. Waithood representa um prolongado período de suspensão entre a infância e a idade adulta. As transições da juventude à idade adulta tornaram-se tão incertas que um número crescente de jovens, rapazes e raparigas, vê-se obrigado a improvisar formas de subsistência e relações interpessoais fora das estruturas económicas e familiares dominantes. A sua situação é particularmente difícil, mas também inspira muitos deles a engendrar soluções criativas (HONWANA, 2014, p. 299)

como no caso da entrada das mulheres no comércio informal.

$\mathrm{Na}$ impossibilidade de compreender a divisão sexual do trabalho em Cabo Verde a partir das teóricas feministas do final do século XX, que partem do pressuposto de que a estrutura nuclear patriarcal euramericana de família é universal, assim como a opressão ao universo feminino que advém dela, como aponta Rodrigues (2007), é interessante perceber o papel do homem no agregado familiar enquanto filho ou irmão, como aponta Lobo (2016), 
como é o caso de Sônia, que tem em seu único filho o braço direito para tomar conta de sua boutique.

\section{Fazer comércio dentro e fora de Mindelo}

Em um país em que a emigração é um valor - simbólico e econômico - tão importante, As remessas são o que mantém a liga entre as pessoas, através do ato de fazer circular, garantindo a presença mesmo que à distância (DEFRAYNE, 2016, p. 157), além de serem importantíssimas para a garantia da reprodução econômica, social e biológica dos agregados familiares que ficara no arquipélago (cf. ÅKESSON, 2011; BRAZ DIAS, 2010; TRAJANO FILHO, 2009). Uma vez que a maior parte dos itens que abastece o mercado cabo-verdiano e/ou chega às casas dos habitantes do arquipélago Cabo Verde vem do exterior, muitos grupos se envolvem nesse processo de fomento de bens para consumo no país.

As rotas mais frequentes traçadas pelas comerciantes são Portugal, Estados Unidos, Brasil, Canárias e Senegal, enquanto Luxemburgo, Bélgica, Alemanha, Itália, Guiné Bissau, Holanda, França e Inglaterra são destinos menos frequentes, mas também utilizadas pelas comerciantes. Dentre esses países, apenas o Brasil, Canárias, Alemanha e Inglaterra são destinos menos frequentes de migração laboral, embora o primeiro seja um importante receptor de estudantes cabo-verdianos em suas universidades (cf. SUBUHANA, 2009). Por serem comerciantes, elas precisam tirar um visto específico para a categoria ${ }^{9}$, cuja validade é de um ano.

Como apontado em outro trabalho,

[c]ada um dos países acima listados fornece para estas mulheres tipos de produtos diferenciados. De forma muito breve podemos afirmar que nos Estados Unidos elas buscam prioritariamente cosméticos e alguns tipos de roupas e sapatos em liquidação (roupas de festa) e dos centros europeus abastecem o mercado local com artigos para casa (cama, mesa e banho) e perfumes "caros". Os mesmos produtos encontrados na Europa, mas com qualidade inferior ou oriundos de falsificação, são adquiridos em Dakar e, finalmente, no Brasil buscam roupas íntimas, artigos infantis, moda praia, sapatos e sandálias Havaianas (LOBO; VENÂNCIO, 2017, p. 32).

Devido à ausência de uma grande feira ou conglomerado comercial do tipo, fator que diferencia o comércio transnacional em Mindelo com o da Praia, que conta com o Mercado

\footnotetext{
${ }^{9}$ Com exceção de Portugal, nenhum outro país possui consulado em São Vicente, embora já tenha existido na virada do século XIX para o XX (CORREIA E SILVA, 2000). Isso gera revolta às moradoras de Mindelo, que têm que arcar com o deslocamento até a capital para dar entrada nos tramites burocráticos da solicitação do visto, o que torna a viagem delas ainda mais dispendiosa, acirrando a competição entre as duas cidades.
} 
do Sucupira, ${ }^{10}$ as comerciantes transnacionais tendem a ser encontradas em boutiques, que se espalham por quase toda a cidade, mas se concentram em sua área central, sendo as donas das boutiques a parcela mais significativa das minhas interlocutoras. As boutiques e casas comerciais lotam as principais ruas da Morada - bairro central de Mindelo, abrindo às $9 \mathrm{da}$ manhã e fechando às $13 \mathrm{~h}$, com intervalo para o almoço até às $15 \mathrm{~h}$, quando os trabalhos recomeçam e seguem até às $18 \mathrm{~h}$ ou $19 \mathrm{~h}$ a depender do pique das vendas.

Outro fator que diferencia o comercio transnacional em Mindelo com o realizado na Praia é a adesão ao termo rabidantes ${ }^{11}$. Mesmo com a dúbia aplicabilidade, utilizo-o aqui devido à etimologia apresentada, que expressa bem a ideia de movimento que perpassa a ações que essas mulheres desenvolvem no âmbito do trabalho, sem muita diferenciação de uma ilha para outra.

Os períodos em que o comércio mindelense tem maior movimentação são durante o verão (de julho a setembro) e as festas de final de ano. O Carnaval, período em que o faturamento das comerciantes transnacionais aumentava substancialmente, vem apresentando queda, uma vez que comerciantes como Célia me mostraram material encalhado de carnavais anteriores que não fora vendido por causa da concorrência "desleal" dos chineses, que estariam fornecendo os produtos que antes elas detinham quase que o monopólio.

Para se preparar para os períodos de intensificação nas vendas, Júlia, a comerciante com quem mantive mais diálogo, costuma viajar em maio/junho e em novembro ou início de dezembro para reabastecer a loja, prática também adotada pelas demais comerciantes da ilha. Todavia, as comerciantes, a depender da demanda de suas lojas, podem viajar em outros períodos, para além dos citados, para outros países, com a frequência bi, tri ou quadrimestral.

Nas viagens para países onde as compras devem ser realizadas no atacado, as comerciantes costumam ir em grupo para dividir as grandes quantidades de itens que têm que comprar. Durante o período de maior afluência econômica no arquipélago, o grupo das comerciantes poderia encher um avião da TACV - Transportes Aéreos de Cabo Verde. Embora suas companheiras de viagem sejam suas concorrentes potenciais, já que estarão vendendo produtos similares, ela afirmou não haver competição entre o grupo, porque "cada uma tem os seus clientes, seus expedientes" ${ }^{\prime 2}$ e mesmo que as lojas sejam próximas umas das outras, cada uma já possui a clientela fixa.

\footnotetext{
${ }^{10}$ Tendo em vista que o número de habitantes da ilha de São Vicente é equivalente a apenas 30\% do contingente populacional da ilha de Santiago, o fluxo de mercadorias em direção à primeira ilha também é menor devido à reduzida demanda, se comparado com o que acontece na capital do país, sendo uma justificativa plausível para a não existência de um aglomerado comercial de mesmo porte.

${ }^{11}$ Devido à controversa adesão ao termo entre as mulheres em Mindelo, principalmente por elas não quererem, em alguns casos, serem confundidas com as mulheres que vendem produtos na rua, farei uso da categoria comerciante para designar o conjunto de mulheres supracitado a partir deste ponto do trabalho. Para além de rabidantes e comerciantes transnacionais, as interlocutoras se apresentaram como importadoras internacionais, empresárias, entre outros.

${ }^{12}$ Os "expedientes" seriam a forma de trabalhar para conquistar a confiança e assiduidade dos clientes.
} 
Quando uma comerciante se vê impossibilitada de realizar uma viagem, ela costuma solicitar que uma amiga que esteja indo traga os produtos que estão em falta - ou quase acabando - no seu estabelecimento. Essa situação inaugura os ciclos de dádivas e contra dádivas que marca a relação das comerciantes que constroem laços de afinidade. $\mathrm{O}$ circuito de trocas e favores entre afins é muito comum na sociedade cabo-verdiana devido à intensidade dos fluxos, principalmente os migratórios, que perpassam o arquipélago (cf. LOBO, 2014).

Contudo, nem só de idas se constitui o comércio de Mindelo. Como forma de driblar os efeitos da crise econômica a qual o país vem enfrentando, as comerciantes passaram a demandar que os parentes emigrados aumentassem a quantidade de produtos por eles enviados. Júlia, por exemplo, conseguiu manter sua boutique com o estoque cheio graças aos bidões que sua mãe, que vive em Brockton, EUA, enviava, mostrando a importância das redes familiares e dos fluxos migratórios não só para o início do comércio, mas também para sua continuidade. Geralmente sua mãe costuma enviar cinco ou seis bidões por vez (por isso a loja estava abarrotada de produtos). Júlia pontuou que os navios costumam sair a cada dois ou três meses, tendo a frequência reduzida no período do inverno pela agitação do mar. Por isso, é importante que os emigrantes fiquem atentos às datas estipuladas pelas agências marítimas.

Mas não é só para driblar a crise que os bidões, forma de envio de remessas por parte dos emigrantes cabo-verdianos anterior à independência, ganham a cena no comércio em São Vicente. Maria, comerciante transnacional que também possuía um salão de beleza nas imediações da praça dr. Regala, por exemplo, reduziu a frequência das viagens assim que o seu filho se mudou para Portugal, onde foi cursar o ensino superior. Além de reduzir o desgaste causado pelas viagens e possibilitar que ela esteja mais presente no salão de beleza que ela possuía, o recebimento dos produtos por meio dos bidões deixa o custo final do produto mais barato, uma vez que o bidão já seria utilizado por ela, de qualquer forma, para enviar os produtos de Portugal para o arquipélago, tendo em vista que transportá-los por via aérea ficaria muito caro devido aos preços do excesso de bagagem.

Júlia me contou que é comum ter extravio de bidões, assim como há de malas com a TACV. Embora atualmente haja mais segurança para enviar os bidões, há reclamações, por parte das minhas interlocutoras, de mercadorias que nunca chegaram, mercadoria que caiu no mar devido à agitação do mar, e algumas comerciantes afirmam que, após deixarem as mercadorias por duas semanas no armazém da ENAPOR (autoridade portuária caboverdiana), elas tiveram suas embalagens violadas e itens furtados. A fala de Célia exemplifica essa situação: "já roubaram mercadoria no armazém da ENAPOR, mercadoria encaixotada, várias vezes. Em 2013 eles roubaram toda a minha mercadoria. Ficaram lá 15 dias e roubaram toda a minha mercadoria. E não só a mim que eles roubam, roubam muita gente" (Trecho da entrevista realizada com Célia em fevereiro de 2017. 
O mesmo pode acontecer se transportados nos aviões, mesmo a tarifa sendo mais cara. Em um incidente com a TACV, Maria, ao voltar do Brasil, acabou perdendo todas as compras, já que a bagagem completa nunca apareceu. A sua

carga foi embarcada, um ano depois apareceram algumas coisas no armazém da TACV, depois de eu ter escrito várias cartas, várias reclamações, diziam que não, que não, afinal as coisas estavam lá, durante um ano, quando tive acesso a elas as coisas já estavam quase todas estragadas. Enfim, perdi o dinheiro porque a única coisa que eles deram foi um bilhete de passagem outra vez pra Fortaleza, mais nada (Trecho da entrevista realizada com Maria em fevereiro de 2017).

Todo esse trabalho e risco na busca por produtos em países específicos tem uma justificativa: no contexto mindelense - e também na cidade da Praia (LOBO, 2012) - a origem dos produtos é crucial para garantir a venda. Nesse contexto, surgem lojas especializadas em produtos de determinados lugares. Por exemplo, as lojas de ex-emigrantes ou de pessoas que têm familiares emigrados - com exceção de Portugal - costumam se especializar em produtos vindos desses países, sempre usando o discurso de que "os produtos de tal lugar são de melhor qualidade”.

É a partir da supervalorização da "origem"13 dos seus produtos que é feita a diferenciação entre as lojas. Enquanto Júlia diz que os clientes têm preferência pelas coisas vindas dos EUA, afirmando que "aqui em Cabo Verde eles preferem os produtos da América por terem mais qualidade" (trecho da entrevista realizada com Júlia em janeiro de 2017). Clementina, ex-emigrante que foi para Itália e hoje é dona de uma boutique e de um barzinho no bairro Ribeira Bote, ressalta os seus produtos italianos, uma vez que, para ela, "na Itália só tem coisas bonitas" (trecho da entrevista realizada com Júlia em janeiro de 2017).

Isso se dá porque elas trabalham como "mediadoras entre os dois universos, manipulam os diferentes valores atribuídos às mercadorias em seu favor para conseguir o melhor lucro" (LOBO, 2015, p. 24). Ainda, o fenômeno de supervalorização da origem ocorre, segundo Kopytoff (1986), por causa do evidente desejo de singularização encontrado no mundo urbano contemporâneo, cuja mercantilização dos produtos ocorre com a operação de inúmeros esquemas de valoração e singularização operacionados pelos grupos sociais. Ou seja, elas só adquirem esse valor por causa das estratégias nas quais elas estão inseridas (FRIEDMAN, 1991).

Portanto, mesmo que sejam produtos de baixa qualidade nos países de origem, o valor atribuído a eles é ressignificado ao longo de seu fluxo para que correspondam às

\footnotetext{
${ }^{13} \mathrm{O}$ termo aparece entre aspas por serem raros os casos em que os produtos adquiridos tenham sido produzidos no país onde eles foram comprados. Com exceção de uma parte dos itens brasileiros, a maior parte dos produtos revendidos pelas comerciantes cabo-verdianas são fabricados em países cujos custos são menores do que se fossem fazê-lo em países de economia "desenvolvida".
} 
expectativas dos compradores, ${ }^{14}$ que querem se ver em pé de igualdade com os consumidores dos países onde as mercadorias são adquiridas. Para entender melhor essa situação passemos para o caso dos produtos brasileiros.

\section{É do produto brasileiro que eles (realmente) gostam?}

Entre os países onde elas vão comprar os produtos que abastecerão as suas boutiques e quiosques, o Brasil é apontado enquanto um dos favoritos. Mesmo que no início da década de 1990 a finada empresa de aviação Varig fizesse a rota Rio de Janeiro - Cabo Verde, foi com a criação de linhas aéreas que conectavam inicialmente a ilha de Sal com Fortaleza, no estado do Ceará, em 2001, pela TACV ${ }^{15}$, que as transações comerciais entre os dois países cresceram exponencialmente. As comerciantes cabo-verdianas impulsionaram a economia de Fortaleza, contribuindo para o surgimento de muitas confecções entre 2002 e 2004. Ainda, estima-se que elas tenham gasto em torno de 5 milhões de dólares aqui só no ano de 2003, levando cerca de 400 toneladas de mercadoria. Durante os anos 2000, algumas das comerciantes transnacionais chegavam a realizar viagens semanais para Fortaleza (LOBO, 2012).

São variados os fatores que podem explicar o porquê de os cabo-verdianos gostarem tanto dos produtos brasileiros. As comerciantes de Mindelo, assim como apontado por Lobo (2012) para o caso do Mercado de Sucupira, alicerçam a preferência pelos produtos brasileiros na originalidade e principalmente na qualidade, característica primordial quando é preciso desqualificar a mercadoria vendida por um(a) concorrente, como é recorrente quando às críticas aos chineses vêm à tona. Sônia, por exemplo, apontou que os produtos brasileiros têm mais saída em sua loja, sendo a sua qualidade até superior à dos produtos europeus. Para justificar sua proposição, ela assegurou que os calçados brasileiros são de tão boa qualidade que ela tem "uns há dois, três anos que continuam novinhos" (trecho da entrevista realizada com Sônia em fevereiro de 2017). Sempre que ela chega de viagem, os produtos brasileiros não costumam durar duas semanas nas prateleiras, do tanto que seus clientes gostam deles.

Outro ponto que pode se relacionar com o sucesso dos produtos brasileiros são as novelas e demais programas televisivos que exportamos para o arquipélago. Enquanto estive lá, a novela Babilônia era exibida em dois horários distintos pela rede de Televisão de Cabo Verde (TCV), assim como o seriado Louco por elas, ambos da Rede Globo. As novelas vendem um estereótipo de Brasil e consumo que é demandado não só por nós, que aqui vivemos, mas também pela população dos países que recebem as nossas telenovelas, como é o caso dos países lusófonos africanos apresentados no trabalho de Mendes (2012). Embora a trilha sonora seja mais fácil de ser adquirida, com a popularização do acesso à internet, as roupas usadas, os produtos anunciados via merchandising e o próprio brazilian way of life

\footnotetext{
${ }^{14}$ Os compradores são pessoas de diferentes classes sociais, embora nas boutiques prevaleçam consumidores de estratos médios. Geralmente eles se fidelizam a uma comerciante e compram produtos sempre delas.

${ }^{15}$ Atualmente a TACV também liga o arquipélago à cidade Recife, trajeto iniciado no ano de 2015.
} 
tornam-se alvos de desejo dos cabo-verdianos, cujo consumo se faz viável por meio das comerciantes transnacionais.

Os produtos brasileiros com maior demanda dos cabo-verdianos são as roupas especialmente as de verão, como shortinhos, biquínis e cangas -, calçados, bijuterias e cosméticos, sem exceção de marca. Quase todo quiosque na Praça Estrela que não é de souvenires revende produtos para cabelo e/ou as famosas Havaianas, de todas as cores, modelos e tamanhos. Elas são tão populares por lá que réplicas - fornecidas majoritariamente pelos chineses - são comuns de serem encontradas nos pés das pessoas, as Heveienes.

O sucesso dos cosméticos brasileiros é tão grande em Mindelo que possibilitou que Senhor Eugênio e dona Helena ${ }^{16}$ migrassem do ramo das roupas e calçados para o de cosméticos, abrindo sua loja em uma das principais ruas da Morada, voltada exclusivamente para essa categoria de produtos, a Feito no Brasil. Dentro do jogo de conseguir menores preços na aquisição dos bens, surge a necessidade de adquirir produtos que não estão no mainstream no Brasil, já que sua saída será garantida pela boa fama que os produtos brasileiros possuem na cidade. No período áureo das vendas, eles chegaram a realizar seis viagens em um mesmo ano para Fortaleza a fim de reabastecer o estoque. Com o encarecimento das passagens, do excesso de bagagem cobrado pela TACV e dos próprios produtos, houve uma redução nas viagens realizadas.

Agora, é a crise brasileira, que com a inflação em alta, aumenta o preço dos produtos e acaba por afastar algumas comerciantes do mercado do Brasil. Ainda, há, em solo brasileiro, outros fatores que têm encarecido as viagens das cabo-verdianas. Nesse contexto, Bia, comerciante de 50 anos e dona de um conjunto de quiosques na Praça Estrela, apontou que "antes, para ir para o Brasil, em termos de encomenda, era mais fácil. Agora para ter documento (visto) fica mais exigente, tem hotel, mercadoria e táxi. Tudo fica mais caro agora", o que acaba refletindo no preço final dos produtos que elas vendem.

Os fatores apontados por elas para justificar a predileção pelo Brasil foram a proximidade, uma vez que o voo não chega a durar quatro horas, e pela facilidade do português enquanto língua do brasil, o que facilita as transações para aquelas que não são fluentes em outros idiomas, como o inglês, embora elas se comuniquem entre elas por meio do crioulo, característica que as diferenciam para os donos das fábricas em Fortaleza (Silva, 2012).

Dentre as dificuldades de se fazer compras em Fortaleza foram elencadas diversas vezes a distância entre os hotéis onde elas se hospedam e as fábricas onde elas compram os seus produtos. Ainda, a violência das cidades brasileiras, que chega ao arquipélago por meio dos programas de caráter sensacionalista, como o Brasil Urgente, é um ponto que costuma

\footnotetext{
${ }^{16} \mathrm{O}$ casal, que trabalha no comércio há quase duas décadas, tem uma história peculiar. Embora seja senhor Eugênio quem faça as viagens transnacionais desde o início da empreitada familiar, além de ter sido ele que abandonou o emprego para realizar o projeto, enquanto sua d. Helena continuava como funcionária pública, ele afirma que é ela quem responde pela loja, tendo em vista que ela controla rigorosamente a entrada e saída do caixa.
} 
assustar essas mulheres, o que os corretores $^{17}$ usam a seu favor para convencer as comerciantes de sua importância junto a elas.

Outro problema que as comerciantes enfrentam quando vêm para o Brasil é o tráfico de drogas. Quando esteve em Fortaleza pela última vez, em março de 2016, Sônia viu uma senhora da Praia ser detida por transportar drogas. No aeroporto, havia muitos policiais, o que a deixou apreensiva. Chegando na Praia, todas as malas foram revistadas, fazendo com que ela e suas companheiras de viagem acabassem por perder o voo para Mindelo, onerando ainda mais as comerciantes.

\section{Considerações finais}

Sendo Cabo Verde uma sociedade onde ocorre a "coexistência de valores e práticas que apontam para a centralidade da posição ocupada pela mulher na organização familiar, ao mesmo tempo em que reforçam uma ideologia onde o homem deve manter-se como centro das tomadas de decisão, da autoridade e do respeito" (BRAZ DIAS, 2001, p. 74), a mulher acaba por se encarregar, também, da reprodução financeira do agregado doméstico. Com isso, as mulheres-mães adentram em no mundo do comércio por ele possibilitar a circulação entre a casa da rua, fazendo da primeira uma extensão da segunda, e vice- versa. Assim, percebe-se que a centralidade da mulher na vida comercial se dá, nos casos apresentados, como uma forma de "se desenrascar e vencer as dificuldades com o uso da criatividade e da esperteza” (TRAJANO FILHO, 2008, p. 250), uma vez que ela aparenta ser uma consequência da sua centralidade na vida doméstica.

Por causa da facilidade de conjugação dos dois mundos que o comércio proporciona, as mulheres acabam por dominar as atividades comerciais, sejam as que envolvem os fluxos transnacionais, sejam as de gêneros alimentícios que têm lugar nas ruas das principais cidades de Cabo Verde (FORTES, 2015b). Assim, boa parte dos lucros obtidos por elas é revertido para as suas famílias, fazendo com que o comércio possa ser compreendido enquanto um projeto familiar, assim como a emigração, uma vez que os seus filhos acabam sendo os principais beneficiários da atividade desempenhada por elas. Enquanto Maria contribui com a formação superior do seu filho em Portugal, Júlia e Sônia economizam os recursos angariados em suas lojas para que seus filhos possam ingressar no ensino superior sem problemas financeiros.

E não só pela perspectiva da garantia da reprodução financeira o comércio transnacional pode ser visto enquanto um projeto familiar, tendo em vista que, muitas vezes, são as famílias as primeiras financiadoras e/ou fornecedoras dos produtos das comerciantes, podendo ser uma ajuda importante em momentos de crise (LOBO; VENÂNCIO, 2017).

Seja na própria casa, na rua ou em lojas, as mulheres cabo-verdianas se transformam em comerciantes, sendo elas a maioria nesse ramo. Por isso, Rodrigues aponta que as

\footnotetext{
${ }^{17}$ Os corretores são pessoas que acompanham as comerciantes durante as compras, levando-as às fábricas e lojas, além de tomar conta das compras que elas fazem. Embora não cobrem diretamente pelo serviço prestado, eles possuem acordos com as fábricas que eles encaminham as cabo-verdianas e faturam em cima das vendas das fábricas.
} 
comerciantes transnacionais formam "uma intrincada rede de agentes económicos femininos independentes" que, "através da economia informal, constroem laços e lucros por todas as ilhas e para além destas” (2007, p. 132), tudo isso em prol de melhorias para o grupo doméstico. Ainda, o comércio transnacional possibilita maior liberdade econômica, uma vez que as mulheres não dependeriam dos seus (possíveis) cônjuges financeiramente em uma sociedade onde a família nuclear patriarcal é um sonho tão desejado.

Por fim, ressalto a importância do desvio do olhar para o comércio em Cabo Verde da cidade da Praia para Mindelo, o que contribuiu para "des-homogeneizar" as cidades que constituem o país, país este que tem nos contrastes uma de suas marcas, percebendo novas realidades e nuances nas práticas comerciais. Mesmo com algumas poucas diferenças, muitas coisas se repetem entre as ilhas. Com certeza, a principal delas é a replicação da centralidade da mulher-mãe cabo-verdiana na vida doméstica para o mundo do comércio, fazendo dele um mundo das mulheres, tendo em vista as justificativas apresentadas por parte das comerciantes para a entrada e permanência nessa atividade laboral, que viabiliza a globalização popular.

\section{Referências Bibliográficas}

ÅKESSON, L. Cape Verdean notions of migrant remittances, Cadernos de Estudos Africanos, 20: 137-159, 2011.

BRAZ DIAS, Juliana. Modelos crioulos de organização familiar em Cabo Verde. Papia, 2001. v. 11, p. $74-80$.

Enviando dinheiro, construindo afetos. In: TRAJANO FILHO, Wilson. Lugares, pessoas e grupos: as lógicas do pertencimento em perspectiva internacional. Brasília: Athalaia Gráfica e editora, 2010. pp. 47-73.

BRENTON, Paul et al. Women an Trade in Africa: Realzing the Potential. 2013. The World Bank. 201p.

BROOKS JR., George E. The Signares of Saint-Louis and Gorée: Women Entrepreneurs in Eighteenth-Century Senegal. In: Hafkin and Bay (Org.) Women in Africa: Studies in Social and Economic Change. Stanford: Stanford University Press, 1976. P. 19 - 44.

CORREIA e SILVA, António Leão. Nos Tempos do Porto Grande do Mindelo. Praia: Centro Cultural Português. 2000. 203p.

DEFRAYNE, Elisabeth. Au rythme des tambor: Ethnographie des mobilités des gens de Santo Antão (Cap-Vert, Belgique, Luxembourg). Thèse (Docteure en Sciences Politiques et Sociales: Anthropologie). Louvain : Université Catholic de Louvain, 2016.

DOMINGUES, Maria Manuela Abreu Borges. Estratégias femininas entre as bideiras de Bissau, Lisboa: Universidade Nova de Lisboa. Tese de doutorado. 2000. 322p.

FORTES, Celeste. "Casa sem homem é um navio à deriva": Cabo Verde, a monoparentalidade e o sonho de uma família nuclear e patriarcal. Anuário Antropológico, Brasília, UnB, 2015a, v. 40, n. 2: 151-172. 
FORTES, Celeste. As vendedeiras de Cabo Verde: circulação de produtos, informalidade e mulheres no espaço público de Cabo Verde. In José Rogério Lopes (Org). Visagens de Cabo Verde: Ensaios de Antropologia Visual e outros ensaios. Brasil. Cirkula, pp.101-121. 2015b.

FRIEDMAN, Jonathan. Consuming Desires: Strategies of Selfhood and Appropriation. Cultural Anthropology vol.6, n.2, 1991.

GRASSI, Marzia. Rabidantes: comércio espontâneo transnacional em Cabo Verde. Instituto de Ciências Sociais e Spleen Edições. 2003. 354p.

GRASSI, Marzia. Economia informal em rede: Trocas económicas e complexidade social. Cadernos de Estudos Africanos, n. 13/14, p. 129-142, 2007.

HANSEN, Karen. Salaula: the world of secondhand clothing and Zambia. Chicago: University of Chicago Press, 2000. 298p.

HONWANA, Alcinda. Juventude, waithood e protestos sociais em África. In: BRITO, Luís et al. (Org.). Desafios para Moçambique 2014. Maputo: IESE, 2014.

INE, s.d. RGPH 2010 - Cabo Verde em Números. Disponível em: http://ine.cv/quadros/rgph2010-cabo-verde-em-numeros/.

INE, 2016. PIB a Preços de Mercado Óptica do Produto 2014 por Ilhas (Milhões de Escudos). Disponível em: http://ine.cv/estatisticas-por-tema/pib-e-componentestrimestral/\#1477419842708-ef3b0490-9ad2077e-ee39

INE, 2017. Mulheres e homens em Cabo Verde. Factos e números.

KOPYTOFF, Igor. The Cultural Biography of Things: Commoditization as Process. In: APPADURAI, Arjun, ed. 1986. The Social Life of Things: Commodities in Cultural Perspective. Cambridge: Cambridge University Press, 1986. p. 64 - 91.

LOBO, Andréa de Souza; VENÂNCIO, Vinicius. Com parente se negocia? Redes migratórias e o comércio transcional em Cabo Verde. In: Cadernos de Campo, revista de ciências sociais da UNESP. n.23, 2017, p.25-44.

LOBO, Andréa de Souza. Negociando pelo mundo: as rabidantes cabo-verdianas e suas rotas comerciais. In: Wilson Trajano Filho. (Org.). Travessias Antropológicas: estudos em contextos africanos. 1ed.Brasília: ABA Publicações, 2012, v. 1, p. 317-338.

Tão Longe Tão Perto: Famílias e movimentos na ilha da Boa Vista de Cabo Verde. Brasília: ABA Publicações, 2014.

É do produto brasileiro que os clientes gostam? as rabidantes e a rota comercial entre Brasil e Cabo Verde. Cuadernos de Antropología Social, v.13, p.15-31, 2015.

Sobre mulheres fortes e homens ausentes? Pensando conjugalidades como processos em Cabo Verde. Sociedade e Cultura, vol.19, n.2, p.13-25, 2016.

LOPES, Carlos M. Comércio informal, transfronteiriço e transnacional: que articulações? Estudo de caso no Mercado de S. Pedro (Huambo) e nos mercados dos Kwanzas e Roque Santeiro (Luanda). Economia Global e Gestão, v. 12, n. 3, p. 35-55, 2007. 
MENDES, Chirley. Uma vitrine do Brasil: Telenovelas brasileiras entre estudantes africanos.

Dissertação de Mestrado. Programa de Pós-Graduação em Antropologia Social, Universidade de Brasília, 2013.

MOUTINHO, Laura; LIBERATO, Rita Simone. Cenas da delicadeza: o trade entre Johanneburg, África do Sul e Maputo, Moçambique. Amazônica. vol.10, n.2. p.816-866, 2018.

NORDSTROM, Carolyn. Global outlaws. Crime, Money and Power in the contemporary world. London: University of California Press. 2007.

RIBEIRO, Gustavo Lins. A Globalização Popular e o Sistema Mundial Não-hegemônico. Revista Brasileira de Ciências Sociais, v. 25, p. 21-38, 2010.

RODRIGUES, Isabel Feo. As mães e os seus filhos dentro da plasticidade parental: reconsiderando o patriarcado na teoria e na prática. In: GRASSI, M. \& ÉVORA, I. (Org.). Género e Migrações Cabo-verdianas. Lisboa: Imprensa de Ciências Sociais, 2007. pp. 123146.

SILVA, Tatiana. A arte de comerciar: gênero, identidades e emancipação feminina no comércio transatlântico das rabidantes cabo-verdianas. Tese de Doutorado. Centro de Estudos Afro-Orientais, Universidade Federal da Bahia, 2012. 156p.

SUBUHANA, Carlos. A experiência sociocultural de universitários da África Lusófona no Brasil: entremenado histórias. Pro-Posições, v. 20, n. 1, p. 103 - 126, 2009.

TRAJANO FILHO, Wilson. O precário equilíbrio entre improvisação e regras: reflexões sobre a cultura política da Guiné-Bissau. In: Revista de Antropologia, vol.51, n.1, p.233266. 2008.

TRAJANO FILHO, W. The conservative aspects of a centripetal diaspora: The case of the Cape Verdean Tabancas, Africa, 79 (4): 520-542, 2009.

\section{autor Vinicius Venâncio}

Mestrando em Antropologia Social e graduado em Ciências Sociais, ambos pela Universidade de Brasília. Integra o Laboratório de Etnologia em Contextos Africanos (ECOA/DAN/UnB)

Recebido em 24/12/2018

Aceito para publicação em 03/05/2019 